\title{
Differences in psychopathology and behavioral characteristics of patients affected by conversion motor disorder and organic dystonia
}

This article was published in the following Dove Press journal:

Neuropsychiatric Disease and Treatment

\section{Adriana Pastore \\ Grazia Pierri \\ Giada Fabio \\ Silvia Ferramosca \\ Angelo Gigante \\ Maria Superbo \\ Roberta Pellicciari \\ Francesco Margari}

Department of Basic Medical Sciences, Neuroscience and Sense Organs, University of Bari "Aldo Moro", Bari, Italy
Correspondence: Adriana Pastore Psychiatry Unit, "Policlinico" Hospital of Bari, Giulio Cesare Square, Number II, 70124 Bari, Italy

Tel +390805478 576

Fax +390805593058

Email adrianapastoreI0@gmail.com
Purpose: Typically, the diagnosis of conversion motor disorder (CMD) is achieved by the exclusion of a wide range of organic illnesses rather than by applying positive criteria. New diagnostic criteria are highly needed in this scenario. The main aim of this study was to explore the use of behavioral features as an inclusion criterion for CMD, taking into account the relationship of the patients with physicians, and comparing the results with those from patients affected by organic dystonia (OD).

Patients and methods: Patients from the outpatient Movement Disorder Service were assigned to either the CMD or the OD group based on Fahn and Williams criteria. Differences in sociodemographics, disease history, psychopathology, and degree of satisfaction about care received were assessed. Patient-neurologist agreement about the etiological nature of the disorder was also assessed using the $k$-statistic. A logistic regression analysis estimated the discordance status as a predictor to case/control status.

Results: In this study, $31 \mathrm{CMD}$ and $31 \mathrm{OD}$ patients were included. CMD patients showed a longer illness life span, involvement of more body regions, higher comorbidity with anxiety, depression, and borderline personality disorder, as well as higher negative opinions about physicians' delivering of proper care. Contrary to our expectations, CMD disagreement with neurologists about the etiological nature of the disorder was not statistically significant. Additional analysis showed that having at least one personality disorder was statistically associated with the discordance status.

Conclusion: This study suggests that CMD patients show higher conflicting behavior toward physicians. Contrary to our expectations, they show awareness of their psychological needs, suggesting a possible lack of recognition of psychological distress in the neurological setting. Keywords: functional movement disorder, patient-doctor relationship, diagnosis, psychopathology

\section{Introduction}

Conversion motor disorders (CMDs), traditionally best known as functional movement disorders (FMDs), are common and constitute the cause of prominent disability. ${ }^{1}$ They are observed in approximately $2 \%-3 \%$ of patients who visit specialists, ${ }^{2}$ are rated at $2.8 \%$ of all hospital-based visits, and account for up to one-third of attendance at neurology outpatient clinics. ${ }^{3,4}$ They are characterized by movement symptoms that are unrelated to an underlying neurological or medical disorder and can resemble any known neurological movement, including tremor, dystonia, myoclonus, paralysis, tics, and gait disorder, ${ }^{5,6}$ although the psychogenic tremor and dystonia are the most common. $^{3,7}$ 
In the field of movement disorders, the art of diagnosis can be difficult: doctors can usually identify and label phenomenology, but it can be very difficult to define the cause. Typically, the diagnosis of CMD is made by a neurologist based on the presence/absence of specific clinical and laboratory findings. The most commonly used clinical criteria, published by Fahn and Williams (FW) in 1988, ${ }^{8}$ include the following: inconsistency of movements over time; incongruence with typical features of organic movement disorders; or persistent relief by psychotherapy, suggestion, or placebo. According to these criteria, physicians could distinguish between "clinically documented", "clinically established", "probable", and "possible" CMD. Recently, Gupta and Lang $^{9}$ proposed the use of new findings, especially electrophysiological, ${ }^{10,11}$ as a refinement of the FW criteria, giving a reasonable boost to doctors' approach toward establishing a positive diagnosis for CMD. Actually, important advances have been made through electrophysiological and, later, neuroimaging studies, showing the presence of abnormal cortical and sensorimotor features in terms of both organic and functional disorders and suggesting the possibility of shared traits underlying both conditions. ${ }^{12-17}$ However, a recent survey of 519 movement disorder specialists found that $24 \%$ of them do not have routine access to neurophysiological assessment. ${ }^{18}$ Despite the fact that researchers have focused on finding the possible alterations of neural circuits explaining the etiology of such disorders, which may be indicative of changes in brain function, CMD cannot clearly be attributed to a structural lesion of the nervous system yet. ${ }^{19}$ Throughout history, and even now, these disorders are assumed to be associated with an abnormal emotional state. ${ }^{7-19}$ There has been an influential historical emphasis on causation by emotional trauma, which is however not supported by epidemiological studies..$^{20,21}$

Diagnosis of CMD could be also made by psychiatrists on the basis of the Diagnostic and Statistical Manual of Mental Disorders (DSM) criteria, even though CMDs are commonly encountered in primary care and other medical settings relative to psychiatric and other mental health settings. ${ }^{7}$ With the latest major changes in the Fifth Edition of the $D S M, 22$ currently, psychiatric diagnosis of "Functional neurological symptom disorder" is not dependent on the absence/presence of a psychological factor that contributes to the initiation or exacerbation of the symptoms or on the ability of a psychiatrist to detect the presence of an underlying psychopathology (as occurred with the diagnosis of "Conversion disorder" when using DSM- $I V$ ). Actually, psychological or psychiatric disturbance is common throughout organic neurological disease as well. ${ }^{9}$ Regardless of the medical/ nonmedical origin of the disorders, a diagnosis of "Somatic symptom disorder", which includes the CMD, is made when it becomes distressing or disruptive to daily life and after a careful clinical judgment of one's maladaptive response of thoughts, feelings, and behaviors toward physical symptoms: finding somatic symptoms of unclear etiology is no more sufficient to make this diagnosis.

The survey of movement disorder specialists by Espay et $\mathrm{l}^{18}$ highlighted that CMD diagnosis continues to be traditionally driven by the exclusion of a wide range of organic illnesses (ie, inappropriate exclusionary diagnosis), rather than by the application of positive criteria (ie, desirable inclusionary diagnosis), and not the least, Morgante et $\mathrm{al}^{23}$ found that the applicability of clinical criteria for inclusionary diagnosis (ie, FW based) is compromised by their insufficient interrater reliability: due to their limited usefulness, especially in classifying uncertain cases, currently available clinical criteria for CMD are considered unreliable and the need for new diagnostic criteria is highly advocated. Due to their pathophysiological complexity and challenging diagnosis, considering also the lack of accurate and reliable tests, ${ }^{24} \mathrm{CMD}$ is still labeled as the "crisis for neurology". ${ }^{25}$

In an attempt to outline the new criteria for a CMD diagnosis, the main aim of our study was to explore the behavioral features of these patients, such as their interpersonal functioning with relatives and others, in particular, the patient-physician relationship, compared to patients affected by organic dystonia (OD). Furthermore, we have divided participants based on their agreement or discordance with neurologists about the etiological nature of their disorder and thereafter computed associations with clinical and psychopathological characteristics that could theoretically influence it. The possible role of such behavioral features as predictors of a CMD diagnosis was also tested. To our knowledge, this is the first study that takes into account both behavioral and psychopathological features of patients affected by CMD.

\section{Patients and methods}

Patients consecutively admitted to the outpatient Movement Disorder Service in the "Policlinico" Hospital of Bari from January 2012 to December 2013 were included in this study if they fulfilled the following inclusion criteria: aged between 18 and 70 years, had at least one movement disorder, and accepted to sign a written informed consent to participate. Mental retardation and current antipsychotic medication intake were considered as exclusion criteria, the first because it could hinder psychopathological assessment, the latter 
because its possible extrapyramidal negative side effects could interfere with the movement disorder. Patients were assigned either to the CMD group or to the OD group on the basis of the diagnosis made by neurologists with subspecialty training in movement disorder. According to FW criteria, ${ }^{8}$ we included as cases patients with a documented diagnosis $(n=5)$, clinically established diagnosis $(n=25)$, and probable diagnosis $(n=1)$ of CMD, whereas patients who fulfilled clinical criteria for OD, gender, and age match formed the control group. Cases and controls could not be matched by their movement disorder clinical phenotype because CMD patients may experience multiple types of abnormal movements.

Following the consultation, all patients were informed about their diagnosis and were subjected to treatment. More specifically, the controls were told they suffered from a neurological disease with an organic origin, whereas the cases were made aware of suffering from a functional neurological disease and were treated with placebo as the first step: those who reported persistent relief were classified as having a documented diagnosis according to FW criteria.

A resident psychiatrist and a trained psychologist performed a wide assessment with regard to psychopathology and interpersonal functioning. In addition, they gathered information on sociodemographics (including number of schooling years and current employment condition), history about the disease (age of onset, as well as number of body regions involved in the disease), and eventual psychiatric drug medication before and after the movement disorder onset.

Psychopathology was assessed using both different psychometric tests (administered by the psychologist) and the Structured Clinical Interview for DSM-IV Axis I Disorders $(\mathrm{SCID}-\mathrm{I})^{26}$ (administered by the resident psychiatrist specifically trained for this purpose), allowing the computing of a range of continuous, categorical, and binary variables.

\section{Psychopathological assessment}

Anxiety was assessed by both the State-Trait Anxiety Inventory (STAI) Form Y-1 and Y-2, ${ }^{27}$ a four-point Likert scale that consists of 40 questions on a self-report basis with three cutoff points on the final score accounting for absence/mildto-moderate/severe anxiety (adjusted for age and gender), and the SCID-I, whereby the diagnostic evaluations were coded as present or absent.

Depression was assessed by both The Beck Depression Inventory (BDI) ${ }^{28}$ a 21 -item self-report using a four-point scale, with three cutoff points on the final score accounting for absence/mild-to-moderate/severe depression (adjusted for age and gender), as well as the SCID-I, whereby the diagnostic evaluations were coded as present or absent.

Dissociative disorders and related symptoms were evaluated by both the Dissociative Disorders Interview Schedule (DDIS), ${ }^{29}$ a 131 -item structured interview developed to provide a complete picture of the range and type of dissociation experiences and the severity of psychopathology associated with these, and the SCID-I. For our purpose, we used 12 out of the 16 different DDIS sections: somatic complaints, substance abuse history, past experiences of somnambulism, trance status or imaginary friend, violence and sexual abuse experienced in childhood, past supernatural or paranormal experiences, borderline personality disorder, dissociative amnesia, dissociative fugue, depersonalization disorder, dissociative identity disorder (DID) and characteristics associated with it (cannot remember the origin of some things in own home; cannot remember events and situations narrated by others; cannot recognize own handwriting). Scoring rules for the instrument are based on DSM-IV scoring rules, and each section score is coded as present/absent or as the number of symptoms detected, as appropriate. SCID-I provides present/absent diagnosis about dissociative disorders too.

Personality disorders were assessed only by SCID-II, ${ }^{30}$ except for the borderline personality disorder, the evaluation of which is included in the DDIS interview too. The study was approved by the ethics committee of "Policlinico" Hospital of Bari where the study took place.

\section{Interpersonal functioning assessment}

For the study purpose, a semistructured interview specifically created by the authors was also conducted: patients were asked nine questions, designed to explore their interpersonal functioning with respect to the neurologists who currently provide care to them, relatives, and work colleagues. First, they were asked to state what they thought to be the etiological nature of their disease and, if they were unable to answer, the question was formulated as enquiring whether they believed it had an organic or a psychological origin. Answers were coded as 0 if the content corresponded to the neurologists' diagnosis (patient-doctor agreement) or one if did not (discordance). Second, patients were asked to say whether neurologists understood their disease, and third, whether they were able to provide the proper care. The fourth question regarded their opinion on the proper care eventually received in the past from other physicians. Further questions investigated whether they felt someone among his/her relatives did not believe he/she was really ill, whether he/she had 
a significant current quarrel with relatives or in the workplace, or whether he/she had a current legal prosecution. The last question aimed to explore the presence of a disease modeling from a person emotionally close to him/her who manifested the same clinical neurological phenotype. All these answers were coded as 0 (yes) or 1 (no).

\section{Statistics}

Statistical analyses were performed using SPSS (version 20) software. First, normality of the data was checked both visually (ie, using a histogram) and with the KolmogorovSmirnov test. Since most variables were not normally distributed and the sample size is quite small, we decided on a conservative approach, computing variables with nonparametric tests.

Group differences in age, age of onset, number of body regions involved, duration of symptoms, and years of education were assessed using Mann-Whitney $U$-test; differences in gender, medication use, marital status, and employment status were investigated using Fisher's test. Group differences in psychopathology and interpersonal functioning were assessed by Mann-Whitney $U$-test for mean values and Fisher's test for frequencies. Patient-neurologist interrater reliability of the dichotomous opinion about the etiological nature of the disorder was assessed using the $k$-statistic. We interpreted $k$-values on the basis of the Landis-Koch classification: $k<0.0$, poor; $k=0-0.2$, slight; $k=0.21-0.4$, fair; $k=0.41-0.6$, moderate; $k=0.61-0.8$, substantial; and $k=0.81-1.0$, almost perfect. Participants were also classified in four configurations according to their agreement or discordance with neurologists on the opinion about the etiological nature of the disorder: we conducted a Kruskal-Wallis test to investigate whether the distribution of participants across these four identity configurations was affected by some relevant clinical characteristics, psychopathology, and interpersonal functioning features. A logistic regression analysis estimated the discordance status as a predictor to case/control status. Odds ratios (ORs), 95\% CIs, and $p$-values were computed. For all tests, $\alpha \leq 0.05$ was considered statistically significant.

\section{Results}

Thirty-one patients with CMD (prevalent clinical phenotype: tremor $=8$, dystonia $=8$, gait disorder $=15$ ) and 31 patients with OD (matched controls) were willing to participate in the study. Differences in demographic and clinical characteristics between the two groups are presented in Table 1. Cases manifested a significant longer duration of illness $(p=0.000)$,
Table I Differences in demographic and clinical characteristics between CMD and OD patients

\begin{tabular}{|c|c|c|c|}
\hline Characteristics & $\begin{array}{l}\text { CMD } \\
(n=31)\end{array}$ & $\begin{array}{l}\text { OD } \\
(n=31)\end{array}$ & $p$-value \\
\hline Male/female & $13 / 18$ & $13 / 18$ & I \\
\hline Age, years & 47.97 (15.37) & $58.29(7.7 I)$ & 0.10 \\
\hline Body regions involved, $n$ (\%) & $2.97(1.47)$ & $1.87(0.92)$ & $0.00 I^{* *}$ \\
\hline Age at onset, years & $42.55(17.16)$ & $46.81(10.03)$ & 0.434 \\
\hline Symptom duration, years & $6.03(6.97)$ & II.65 (7.95) & $0.000 * *$ \\
\hline Education, years & $9.90(3.37)$ & $9.61(3.36)$ & 0.751 \\
\hline Marital status, n (\%) & & & 0.147 \\
\hline Unmarried & 7 (22\%) & $2(6 \%)$ & - \\
\hline Married/cohabitee & $22(72 \%)$ & $28(91 \%)$ & - \\
\hline Divorced & $2(6 \%)$ & 0 & - \\
\hline Widowed & 0 & I (3\%) & - \\
\hline Employment, n (\%) & & & 0.106 \\
\hline Unemployed & 17 (55\%) & $24(77 \%)$ & - \\
\hline Employed & 14 (45\%) & $7(23 \%)$ & - \\
\hline Retired & $6(19 \%)$ & $13(42 \%)$ & - \\
\hline $\begin{array}{l}\text { Medication use before } \\
\text { onset, } \mathrm{n}(\%)\end{array}$ & & & 1.000 \\
\hline Antidepressant & $3(10 \%)$ & $2(6 \%)$ & - \\
\hline Benzodiazepine & $2(6 \%)$ & I (3\%) & - \\
\hline Anticonvulsant & 0 & 0 & - \\
\hline Antipsychotic & 0 & 0 & - \\
\hline None & $28(90 \%)$ & $28(90 \%)$ & - \\
\hline $\begin{array}{l}\text { Medication use after onset, } \\
\mathrm{n}(\%)\end{array}$ & & & 0.444 \\
\hline Antidepressant & $9(29 \%)$ & 7 (23\%) & - \\
\hline Benzodiazepine & $9(29 \%)$ & $9(29 \%)$ & - \\
\hline Anticonvulsant & $3(10 \%)$ & I (3\%) & - \\
\hline Antipsychotic & $2(6 \%)$ & $3(10 \%)$ & - \\
\hline None & 15 (48\%) & $19(61 \%)$ & - \\
\hline
\end{tabular}

Notes: $* * p<0.005$ for Mann-Whitney U-test; significant $p$-values were confirmed by using parametric test (Student's $t$-test); scores are reported as mean (SD), unless stated otherwise.

Abbreviations: CMD, conversion motor disorder; OD, organic dystonia.

although age at onset was slightly lower, and more body regions were involved ( $p=0.001)$. Moreover, we detected differences in the marital status and employment status, the cases being more frequently unmarried and employed compared to controls, although statistical significance was not reached. The two groups were similar with respect to years of education and medication use both before and after the onset of illness.

Psychopathological differences between the two groups are reported in Table 2 . Cases reported significantly higher scores of the following traits: anxiety $(p=0.05)$, depression ( $p=0.028)$, and borderline personality disorder $(p=0.000)$; in addition, cases showed higher rates of any personality disorder ( $p=0.011)$. Furthermore, we detected significantly higher rates of characteristics associated with DID, such as difficulty in remembering the origin of some things in their own home, difficulty in remembering events and situations 
Table 2 Differences in psychopathology between CMD and OD patients

\begin{tabular}{|c|c|c|c|}
\hline Psychopathology & $\begin{array}{l}\text { CMD } \\
(n=31)\end{array}$ & $\begin{array}{l}\text { OD } \\
(n=3 I)\end{array}$ & $p$-value \\
\hline Any anxiety disorder, $\mathrm{n}(\%)^{\mathrm{a}}$ & $19(61 \%)$ & 14 (45\%) & 0.309 \\
\hline State anxiety (STAI Y-I) & $49.35(9.15)$ & $47.55(9.18)$ & 0.331 \\
\hline Absence & $27(87 \%)$ & $28(9 \mid \%)$ & - \\
\hline Mild-to-moderate & $4(13 \%)$ & I (3\%) & - \\
\hline Severe & 0 & $2(6 \%)$ & - \\
\hline Trait anxiety (STAI Y-2) & $56.58(14.13)$ & $49.74(10.16)$ & $0.05^{*, \mathrm{~b}}$ \\
\hline Absence & $18(58 \%)$ & $26(84 \%)$ & - \\
\hline Mild-to-moderate & 7 (23\%) & $5(16 \%)$ & - \\
\hline Severe & $6(19 \%)$ & 0 & - \\
\hline $\begin{array}{l}\text { Any depression disorder, } \\
\mathrm{n}(\%)^{\mathrm{a}}\end{array}$ & $18(58 \%)$ & 12 (39\%) & 0.204 \\
\hline Depression (BDI) & $17.55(13.11)$ & $9.90(7.43)$ & $0.028^{*, b}$ \\
\hline Absence & $13(42 \%)$ & $22(72 \%)$ & - \\
\hline Mild-to-moderate & $8(26 \%)$ & $2(6 \%)$ & - \\
\hline Severe & $10(32 \%)$ & $7(23 \%)$ & - \\
\hline $\begin{array}{l}\text { Any dissociative disorder, } \\
\mathrm{n}(\%)\end{array}$ & $3(10 \%)$ & 0 & 0.238 \\
\hline Dissociative amnesia & $3(10 \%)$ & 0 & - \\
\hline Dissociative fugue & 0 & 0 & - \\
\hline Depersonalization disorder & 0 & 0 & - \\
\hline DID & 0 & 0 & - \\
\hline \multicolumn{4}{|l|}{ Dissociative symptoms } \\
\hline Somatic complaints, n (\%) & 14 (45\%) & $9(29 \%)$ & 0.293 \\
\hline Any substance abuse, $\mathrm{n}(\%)$ & $2(6 \%)$ & 0 & 0.492 \\
\hline $\begin{array}{l}\text { Any somnambulism/trance/ } \\
\text { friend, } n(\%)\end{array}$ & $3(10 \%)$ & 0 & 0.238 \\
\hline Violence in childhood, $\mathrm{n}(\%)$ & $4(13 \%)$ & 0 & 0.113 \\
\hline Abuse in childhood, $n(\%)$ & $5(16 \%)$ & $2(6 \%)$ & 0.425 \\
\hline $\begin{array}{l}\text { Characteristics associated } \\
\text { with DID }\end{array}$ & $0.32(\mathrm{I} .0 \mathrm{I})$ & 0 & $0.04^{*, b}$ \\
\hline Supernatural/paranormal & $0.26(1.26)$ & 0 & 0.154 \\
\hline $\begin{array}{l}\text { Any personality disorders, } \\
n(\%)^{c}\end{array}$ & II (35\%) & $2(6 \%)$ & $0.01 I^{*, d}$ \\
\hline BPD (DDIS) & $1.06(1.59)$ & 0 & $0.000^{* *, \mathrm{~b}}$ \\
\hline
\end{tabular}

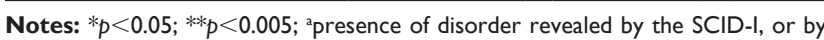

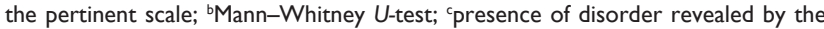
SCID-II; 'Fisher's test; all the significant $p$-values were confirmed by using parametric test (Student's $t$-test or chi-squared test as appropriate), except for difference in "Characteristics associated with DID". Scores are reported as mean (SD), unless stated otherwise.

Abbreviations: BDI, Beck Depression Inventory; BPD, borderline personality disorder; CMD, conversion motor disorder; DDIS, Dissociative Disorders Interview Schedule; DSM, Diagnostic and Statistical Manual of Mental Disorders; DID, dissociative identity disorder; OD, organic dystonia; SCID-I, Structured Clinical Interview for DSM-IV Axis I Disorders; SCID-II, Structured Clinical Interview for DSM-IV Axis II Personality Disorders; STAI, State-Trait Anxiety Inventory Form.

narrated by others, and inability to recognize own handwriting $(p=0.04)$. Although the cases showed higher scores/rates in most other domains, differences with controls did not reach statistical significance.

Differences between the two groups, with respect to interpersonal functioning, are reported in Table 3. Contrary to our expectations, patient-neurologist discordance on the etiological nature of the movement disorder was not significantly
Table 3 Differences in interpersonal functioning between CMD and $O D$ patients

\begin{tabular}{llll}
\hline Interpersonal functioning & $\begin{array}{l}\text { CMD } \\
(\mathbf{n}=\mathbf{3} \mathbf{I})\end{array}$ & $\begin{array}{l}\text { OD } \\
(\mathbf{n}=\mathbf{3} \text { I) }\end{array}$ & p-value \\
\hline $\begin{array}{l}\text { Disagreement on the etiology of } \\
\text { disorder }\end{array}$ & $20(64 \%)$ & $16(52 \%)$ & 0.265 \\
$\begin{array}{l}\text { Negative opinion on neurologists' } \\
\text { understanding }\end{array}$ & $25(80 \%)$ & $16(52 \%)$ & $0.004^{* *}$ \\
$\begin{array}{l}\text { Negative opinion on neurologists' } \\
\text { proper care }\end{array}$ & $21(68 \%)$ & $14(45 \%)$ & $0.030 *$ \\
$\begin{array}{l}\text { Negative opinion on care received } \\
\text { from past physicians }\end{array}$ & $18(58 \%)$ & $23(74 \%)$ & 0.232 \\
$\begin{array}{l}\text { Current quarrels with relatives } \\
\text { Current quarrels with work colleagues }\end{array}$ & $9(29 \%)$ & $8(26 \%)$ & 0.610 \\
$\begin{array}{l}\text { Current legal prosecutions } \\
\text { Having a close person who does not } \\
\text { believe }\end{array}$ & $3(10 \%)$ & $3(10 \%)$ & 0.500 \\
\begin{tabular}{l} 
Presence of disease model \\
\hline
\end{tabular} & $18(58 \%)$ & $7(23 \%)$ & 0.236 \\
\hline
\end{tabular}

Notes: $* p<0.05 ; * * p<0.005$ for Fisher's test; all the significant $p$-values were confirmed by using parametric test (chi-squared test); scores are reported as mean (SD), unless stated otherwise.

Abbreviations: CMD, conversion motor disorder; OD, organic dystonia.

higher among CMD patients than among controls $(p=0.265)$, though a higher number $(\mathrm{n}=20)$ disagreed with doctors compared to controls $(n=16)$ (Table 3$)$. However, what cases significantly showed is the higher frequency of negative opinions about the doctors' understanding of the disease and delivering of proper care ( $p=0.004$ and $p=0.030$, respectively). Furthermore, within each group, these negative answers were highly associated with each other (CMD, $p=0.022$; OD, $p=0.045$ ), as they were with the patients' discordance on the etiological nature ( $p=0.021$ and $p=0.071$, respectively). As regards to the past care received from other physicians, the two groups did not significantly differ from each other, but within the same group, an association was found with those who reported discordance on the etiological nature $(p=0.027)$. Among those who reported a negative answer for neurologists' understanding, the proportion of female gender was slightly higher, both in CMD and in controls (55\% and 56\%, respectively). Similar was the situation for the question about proper care received, but only in the CMD group (57\% against $43 \%$ ). Gender differences within the same group were compared using Fisher analysis and did not show statistically significant results. About interpersonal functioning with relatives and work colleagues, the two groups did not differ in terms of the level of current quarrels or legal prosecutions, nor was a statistically significant difference found in the number of patients believing that someone does not trust that they are really ill (CMD, $\mathrm{n}=12 ; \mathrm{OD}, \mathrm{n}=7 ; p=0.099)$. The latter characteristic showed a trend for an association with patients' discordance about etiological nature $(p=0.068)$. The results 
Table 4 Distribution of participants across the four agreement/discordance configurations

\begin{tabular}{|c|c|c|c|c|c|}
\hline Characteristics & $\begin{array}{l}\text { CMD } \\
\text { agreement }\end{array}$ & $\begin{array}{l}\text { CMD } \\
\text { discordance }\end{array}$ & $\begin{array}{l}\text { OD } \\
\text { agreement }\end{array}$ & $\begin{array}{l}\text { OD } \\
\text { discordance }\end{array}$ & $p$-value \\
\hline Any anxiety disorder ${ }^{a}$ & 63.6 & $60(+)$ & $40(-)$ & 37.5 & 0.579 \\
\hline Any depression disorder ${ }^{a}$ & 54.5 & $60(+)$ & 40 & 50 & 0.488 \\
\hline Any personality disorder ${ }^{b}$ & 27.3 & $40(+)$ & $6.7(-)$ & $6.3(-)$ & $0.035 *$ \\
\hline Legal prosecutions & 27.3 & $0(-)$ & 20 & 18.8 & 0.143 \\
\hline Marital status & 81.8 & $75(-)$ & 93.3 & 93.8 & 0.319 \\
\hline Employment status & 36.4 & $50(+)$ & 26.7 & $18.8(-)$ & 0.228 \\
\hline Medication use after onset & $72.7(+)$ & 40 & $26.7(-)$ & 50 & 0.121 \\
\hline
\end{tabular}

Notes: Data are expressed in percentages. Observed values indicated in bold are significantly $( \pm 2)$ different from expected values: $(+)$ indicates that the observed value is

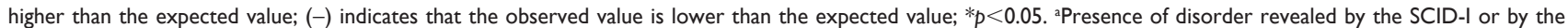
pertinent scale; b presence of disorder revealed by the SCID-II.

Abbreviations: CMD, conversion motor disorder; DSM, Diagnostic and Statistical Manual of Mental Disorders; OD, organic dystonia; SCID-I, Structured Clinical Interview for DSM-IV Axis I Disorders; SCID-II, Structured Clinical Interview for DSM-IV Axis II Personality Disorders.

for the question exploring the modeling disease almost reached statistical significance, since 18 cases had a person emotionally close to him/her who manifested the same clinical neurological phenotype, against 11 controls (58\% and $35 \%$, respectively; $p=0.063$ ).

Within each group, significant associations were detected between psychopathological and interpersonal functioning features: among controls, quarrels with relatives were higher among those who had at least one anxiety disorder $(p=0.007)$ and positive answers toward proper care were associated with the absence of trait anxiety ( $p=0.043$ ). Among cases, those without any personality disorder more frequently stated that someone emotionally close to him/her did not believe that they were real ill persons.

As might be expected considering a nonsignificant difference in the discordance with neurologist about the etiological nature, the logistic regression analysis estimated a nonsignificant association of such discordance status with case/control status ( $p=0.792$ ). Then, we performed the logistic regression analysis for the two significant differences exhibited between the two groups (negative opinion about the neurologists' understanding of the disease and delivering of proper care), given that they are also very similar in meaning to the statement of discordance, but statistical significance was not reached too ( $p=0.144 ; p=0.317$, respectively).

When we looked into the four configurations, set on the basis of participants' agreement/discordance status about the etiological nature of their disorder, and their relationship with psychopathological, sociodemographic, and functioning features, we found that most of the variance was exhibited by the patients affected by CMD who disagreed with neurologists. Actually, Table 4 shows the Fisher's test results explained by the differences in the four configurations, wherein the observed values in bold are significantly
$( \pm 2)$ higher or lower than the expected values. The "CMD discordance" yielded most of the total differences compared to other configurations, which means that although with nonstatistical significance, a trend for a relationship with some features is detectable. Then, it could be speculated that these patients probably have more anxiety, depression or personality disorder, are employed, have less legal prosecutions, and are not married. In the same way, patients affected by CMD who agreed with neurologists had more likely used psychotropic medication after the disorder onset. Furthermore, no significant differences in any observed values compared to expected values were detected in other features, such as dissociative disorder, dissociative symptoms, history of past violence, and sexual abuse. About other interpersonal functioning features related to doctors, we already reported the significant association they showed with each other; for this reason, we considered it redundant to note down the variances for the different configurations. What is notable is that no significant difference in the four configurations was found in terms of current quarrels with relatives and work colleagues. Finally, looking at the relationships between patients in disagreement and sociodemographics, a shorter illness life span and a higher number of body regions involved in the disease exhibited statistical significance in favor of cases ( $p=0.001$ and $p=0.000$, respectively), whereas only a trend toward a lower age was observed ( $p=0.084)$. Overall, patientneurologist interrater reliability was only minor $(k=0.129)$.

\section{Discussion}

Our study aimed to investigate the behavioral and psychopathological profiles of patients affected by CMD compared with those affected by OD, with particular attention to the physician-patient relationship. The study was conducted in a specialist setting, the Movement Disorder Service at the 
Neurological Clinic of our hospital. Actually, it is well known that many general practitioners experience difficulties in establishing communication and relation with CMD patients and, more in general, with symptoms that they cannot explain by physical disease, often indicating them by terms such as "difficult" 31,32 and "heartsink"; 33 to our knowledge, data are lacking for patients attending a specialist setting. Our results showed that patients with CMD, in addition to exhibiting typical clinical characteristics such as longer illness life span, involvement of more body regions, and well-known psychopathological comorbidities such as anxiety and depression, present some behavioral features toward neurologists that are indicative of impairment in the interpersonal functioning area. Patients with CMD have higher frequency of negative opinion both about neurologists' understanding of the disease and delivering of proper care, showing a conflict level that seems to be selective for the neurologist relation: neither negative opinion about care received from past physicians nor current quarrels with relatives/colleagues/others have been detected as having significantly higher frequency compared to the OD group. If we look at associations between different variables within each group, we can find only one significant result that links the presence of an anxiety disorder to higher frequency of quarrels with relatives in the OD group. Probably, it is the relatively small sample size that does not allow us to speculate upon possible associations in the CMD group for the level of conflicts with doctors and other psychopathological features. However, even if this had been possible, we could not state a unidirectional link, since conversely, it could be supposed that such discord is a marker of high level of depression, anxiety, and personality disorders that we detected also to be higher in CMD patients compared to OD patients. Contrary to our expectations, a relatively low proportion of cases disagreed with neurologists about the etiological nature of the disorder ( 11 out of 31 patients said that their disorder had a psychological origin) and what is more notable, more than half of the controls said their disorder had a psychological origin, thus showing disagreement with an OD diagnosis (16 out of 31 ): given the low difference in frequency between the two groups, discordance with doctors did not reach statistical significance. This is in contrast with the wide attribution, by both researchers and general practitioners, of difficulty in relationship to patients' belief that symptoms are caused by physical disease, their consequent insistence on biomedical intervention, and their denial of psychological needs. ${ }^{34,35}$ Rather, our results suggest a lack of recognition of psychological distress that affects primary care patients, ${ }^{36-38}$ as well as patients in a specialist setting, and, at the same time, the high proportion of CMD patients who were willing to accept psychological distress as an explanation for their disorder.

We conducted additional analyses distributing all participants across four configurations according to their agreement/ discordance status with neurologists about the etiological nature of the disorder, in order to detect further associations with psychopathological features. Results showed that having at least one personality disorder is statistically associated with the discordance status. Furthermore, regarding the four configurations, let us check which subgroup explained most of the variance within the statistical test, even though statistical significance was not reached, probably due to the relatively small sample size. Then, considering the values that differed \pm 2 from expected values, we could then speculate that anxiety disorder and depression disorder too could be higher in those CMD patients who did not accept psychological distress as an explanation for their disorder. Once more, such patients would probably be not married and be employed, but with a lower probability of having used a psychotropic medication after the onset of the disorder.

We consider it important to underline that neither statistically significant association nor significant observed values in the four configurations were detected in relation to higher rates of sexual abuse and violence in childhood. Detection of past trauma in CMD patients has long been controversial in the scientific literature. ${ }^{20,21,39}$ Kranic et al, ${ }^{21}$ in a study in 2011 , found that CMD patients' scores were greater in a questionnaire assessing childhood trauma, in reporting number of traumatic events in the past, and in higher self-rated anxiety and depression, compared to healthy controls and patients with focal dystonia. However, the list of variables in which no differences could be found, including gender, frequency of sexual abuse, physical abuse, emotional neglect, parental bonding, a self-report measure of recent life events, interviewer-rated $D S M-I V$ disorders, self-reported personality traits including neuroticism, and a measure of tendency to dissociation, was very large. Other reviews identified female gender, early age of onset, selective disability, history of a precipitating event, possible secondary gain, and comorbid psychiatric disease as frequent characteristics of CMD. ${ }^{40}$ According to these findings, psychological factors play a crucial role in the psychopathology of CMD, but differently from previous beliefs, the association with childhood and lifetime physical and sexual abuse trauma has been demonstrated to be less preeminent than expected.

Finally, in our study, we detected - in the CMD group higher rates of comorbidity with psychiatric disorders such as 
anxiety, depression, any personality disorder, and borderline personality disorder. This finding is so typical of CMD that recently it has been hypothesized that mood and anxiety symptoms may be an integral part of the presentation of CMD. ${ }^{41}$ In conclusion, our data suggest that CMD patients manifest selective discord toward neurologists as a singular behavioral trait. Having at least a personality disorder is the finding that is mostly associated with patients' unwillingness to accept a conversion disorder diagnosis, though a trend was found for anxiety and depression too. However, we emphasize that further studies are required to confirm such findings, using a wider sample size, gathering more information from relatives or medical records, and ruling out current psychotropic medication intake as a possible confounding effect.

\section{Conclusion}

This study suggests that CMD patients show higher conflicting behavior toward physicians. Contrary to our expectations, they show awareness of their psychological needs, suggesting a possible lack of recognition of psychological distress in the neurological setting.

\section{Acknowledgment}

We thank the study participants, without whom this study could not have been accomplished, as well as the staff of the "Policlinico" Hospital of Bari, especially Professor Giovanni Defazio.

\section{Disclosure}

The authors report no conflicts of interest in this work.

\section{References}

1. Carson AJ, Best S, Postma K, Stone J, Warlow C, Sharpe M. The outcome of neurology outpatients with medically unexplained symptoms: a prospective cohort study. J Neurol Neurosurg Psychiatry. 2003;74(7): 897-900.

2. Reich SG. Psychogenic movement disorders. Semin Neurol. 2006; 26(3):289-296.

3. Ertan S, Uluduz D, Ozekmekçi S, et al. Clinical characteristics of 49 patients with psychogenic movement disorders in a tertiary clinic in Turkey. Mov Disord. 2009;24(5):759-762.

4. Edwards MJ, Bhatia KP. Functional (psychogenic) movement disorders: merging mind and brain. Lancet Neurol. 2012;11(3):250-260.

5. Feinstein A, Stergiopoulos V, Fine J, Lang AE. Psychiatric outcome in patients with a psychogenic movement disorder: a prospective study. Neuropsychiatry Neuropsychol Behav Neurol. 2001;14(3):169-176.

6. Peckham EL, Hallett M. Psychogenic movement disorders. Neurol Clin. 2009;27(3):801-819.

7. Bhatia KP, Schneider SA. Psychogenic tremor and related disorders. J Neurol. 2007;254(5):569-574.

8. Fahn S, Williams DT. Psychogenic dystonia. Adv Neurol. 1988;50: 431-455.
9. Gupta A, Lang AE. Psychogenic movement disorders. Curr Opin Neurol. 2009;22(4):430-436.

10. Zeuner KE, Shoge RO, Goldstein SR, Dambrosia JM, Hallett M. Accelerometry to distinguish psychogenic from essential or parkinsonian tremor. Neurology. 2003;61(4):548-550.

11. Esposito M, Edwards MJ, Bhatia KP, Brown P, Cordivari C. Idiopathic spinal myoclonus: a clinical and neurophysiological assessment of a movement disorder of uncertain origin. Mov Disord. 2009;24(16): 2344-2349.

12. Kobayashi K, Lang AE, Hallett M, Lenz FA. Thalamic neuronal and EMG activity in psychogenic dystonia compared with organic dystonia. Mov Disord. 2011;26(7):1348-1352.

13. Espay AJ, Morgante F, Purzner J, Gunraj CA, Lang AE, Chen R. Cortical and spinal abnormalities in psychogenic dystonia. Ann Neurol. 2006;59(5):825-834.

14. Avanzino L, Martino D, van de Warrenburg BP, et al. Cortical excitability is abnormal in patients with the "fixed dystonia" syndrome. Mov Disord. 2008;23(5):646-652.

15. Morgante F, Tinazzi M, Squintani G, et al. Abnormal tactile temporal discrimination in psychogenic dystonia. Neurology. 2011;77(12): 1191-1197.

16. Quartarone A, Rizzo V, Terranova C, et al. Abnormal sensorimotor plasticity in organic but not in psychogenic dystonia. Brain. 2009;132(Pt 10): 2871-2877.

17. Voon V, Brezing C, Gallea C, et al. Emotional stimuli and motor conversion disorder. Brain. 2010;133(5):1526-1536.

18. Espay AJ, Goldenhar LM, Voon V, Schrag A, Burton N, Lang AE. Opinions and clinical practices related to diagnosing and managing patients with psychogenic movement disorders: an international survey of movement disorder society members. Mov Disord. 2009;24(9):1366-1374.

19. Nowak DA, Fink GR. Psychogenic movement disorders: etiology, phenomenology, neuroanatomical correlates and therapeutic approaches. Neuroimage. 2009;47(3):1015-1025.

20. Stone J, Edwards MJ. How "psychogenic" are psychogenic movement disorders? Mov Disord. 2011;26(10):1787-1788.

21. Kranick S, Ekanayake V, Martinez V, Ameli R, Hallett M, Voon V. Psychopathology and psychogenic movement disorders. Mov Disord. 2011;26(10):1844-1850.

22. Stone J, LaFrance WC Jr, Brown R, Spiegel D, Levenson JL, Sharpe M. Conversion disorder: current problems and potential solutions for DSM-5. J Psychosom Res. 2011;71(6):369-376.

23. Morgante F, Edwards MJ, Espay AJ, Fasano A, Mir P, Martino D. DISMOV-SIN study group on psychogenic movement disorders. Diagnostic agreement in patients with psychogenic movement disorders. Mov Disord. 2012;27(4):548-552.

24. Crimlisk HL, Bhatia K, Cope H, David A, Marsden CD, Ron MA. Slater revisited: 6 year follow up study of patients with medically unexplained motor symptoms. BMJ. 1998;316(7131):582-586.

25. Hallett M. Psychogenic movement disorders: a crisis for neurology. Curr Neurol Neurosci Rep. 2006;6(4):269-271.

26. Michael BF, Robert LS, Miriam G, Janet Williams BW. Structured Clinical Interview for DSM-IV-TR Axis I Disorders, Research Version, Patient Edition. (SCID-I/P). New York: Biometrics Research, New York State; 2002.

27. Spielberger CD, Gorssuch RL, Lushene PR, Vagg PR, Jacobs GA. Manual for the State-Trait Anxiety Inventory. Palo Alto, CA: Consulting Psychologists Press, Inc; 1983.

28. Beck AT, Steer RA. Internal consistencies of the original and revised Beck Depression Inventory. J Clin Psychol. 1984;40(6):1365-1367.

29. Ross CA, Helier S, Norton R, Anderson D, Anderson G, Barchet P. The dissociative disorders interview schedule: a structured interview. Dissociation. 1989;2(3):171.

30. First MB, Gibbon M, Spitzer RL, Williams JBW, Benjamin LS. Structured Clinical Interview for DSM-IV Axis II Personality Disorders, (SCID-II). Washington, DC: American Psychiatric Press, Inc; 1997.

31. Anstett R. The difficult patient and the physician-patient relationship. J Fam Pract. 1980;11(2):281-286. 
32. Clements WM, Haddy R, Backstrom D. Managing the difficult patient. J Fam Pract. 1980;10(6):1079-1083.

33. O'Dowd TC. Five years of 'heartsink' patients in general practice. Br Med J. 1988;297(6647):528-530.

34. Goldberg D, Bridges K. Somatic presentations of psychiatric illness in primary care settings. J Psychosom Res. 1988;32(2):137-144.

35. Reid S, Whooley D, Crayford T, Hotopf M. Medically unexplained symptoms: general practitioners' attitudes towards their cause and management. Fam Pract. 2001;18(5):519-523.

36. Borus JF, Howes MJ, Devins NP, Rosenberg R, Livingston WW. Primary health care providers' recognition and diagnosis of mental disorders in their patients. Gen Hosp Psychiatry. 1988;10(5):317-321.
37. Kirmayer LJ, Robbins JM, Dworkind M, Yaffe MJ. Somatization and the recognition of depression and anxiety in primary care. Am J Psychiatry. 1993;150(5):734-741.

38. Ormel J, Koeter MW, van den Brink W, van de Willige G. Recognition, management, and course of anxiety and depression in general practice. Arch Gen Psychiatry. 1991;48(8):700-706.

39. Jankovic J. "Psychogenic" versus "functional" movement disorders? That is the question. Mov Disord. 2014;29(13):1697-1698.

40. Shill H, Gerber P. Evaluation of clinical diagnostic criteria for psychogenic movement disorders. Mov Disord. 2006;21(8):1163-1168.

41. LaFrance WC Jr, Barry JJ. Update on treatments of psychological nonepileptic seizures. Epilepsy Behav. 2005;7(3):364-374.
Neuropsychiatric Disease and Treatment

\section{Publish your work in this journal}

Neuropsychiatric Disease and Treatment is an international, peerreviewed journal of clinical therapeutics and pharmacology focusing on concise rapid reporting of clinical or pre-clinical studies on a range of neuropsychiatric and neurological disorders. This journal is indexed on PubMed Central, the 'PsycINFO' database and CAS,

\section{Dovepress}

and is the official journal of The International Neuropsychiatric Association (INA). The manuscript management system is completely online and includes a very quick and fair peer-review system, which is all easy to use. Visit http://www.dovepress.com/testimonials.php to read real quotes from published authors.

Submit your manuscript here: http://www.dovepress.com/neuropsychiatric-disease-and-treatment-journal 